\title{
INTERLEUKIN 6 INDUCTION IN THE CANINE MYOCARDIUM AFTER CARDIOPULMONARY BYPASS
}

William J. Dreyer, MD ${ }^{\mathrm{a}, \mathrm{b}}$

Sharon C. Phillips, BS ${ }^{\mathrm{a}}$

Merry L. Lindsey, $\mathrm{PhD}^{\mathrm{b}}$

Peggy Jackson ${ }^{\mathrm{b}}$

Neil E. Bowles, $\mathrm{PhD}^{\mathrm{a}}$

Lloyd H. Michael, $\mathrm{PhD}^{\mathrm{b}}$

Mark L. Entman, MD $^{\mathrm{b}}$
Objective: Interleukin 6 is a proinflammatory cytokine with a plasma concentration that has been noted to increase in response to cardiopulmonary bypass. The source of interleukin 6 after cardiopulmonary bypass is unknown. This study examined the myocardium as a potential source of interleukin 6 in this context.

Methods: Dogs underwent 90 minutes of hypothermic cardiopulmonary bypass with 60 minutes of cardioplegic arrest. After rewarming, they were reperfused with the chest open for either $3(n=4)$ or $6(n=4)$ hours, at the end of which myocardial samples were obtained. Four additional animals undergoing open thoracotomy without bypass served as time-matched controls. Northern blot analysis, reverse transcriptase-polymerase chain reaction, and in situ hybridization were used to examine the myocardium for the induction of interleukin 6 and intercellular adhesion molecule-1.

Results: Northern blot analysis and reverse transcriptase-polymerase chain reaction demonstrated a marked increase in myocardial interleukin 6 messenger RNA in 3 of 4 dogs at 3 hours after bypass and 3 of 4 dogs at 6 hours after bypass, which was not present in sham-bypass control animals. Northern blots at 3 hours after cardiopulmonary bypass also demonstrated myocardial intercellular adhesion molecule-1 induction. In situ hybridization studies confirmed that cardiac myocytes were a principal source of interleukin 6 messenger RNA early after cardiopulmonary bypass. Northern blots of messenger RNA extracted from isolated neutrophils and mononuclear leukocytes obtained from blood samples before bypass, at the end of bypass, and 3 hours after bypass failed to demonstrate interleukin 6 induction.

Conclusion: Despite protection with cold cardioplegic arrest, the myocardium was a significant source of interleukin 6 synthesis after cardiopulmonary bypass. Local production of interleukin 6 may play a pivotal role in postoperative myocardial function. (J Thorac Cardiovasc Surg 2000;120:256-63)
From the Lillie Frank Abercrombie Section of Cardiology, Department of Pediatrics, ${ }^{\mathrm{a}}$ and the Section of Cardiovascular Sciences, Department of Medicine, ${ }^{b}$ Baylor College of Medicine, Houston, Tex.

This work was supported in part by grant HL-42550 from the National Institutes of Health and by grant 96G-1188 from the American Heart Association, Texas Affiliate.

Received for publication Nov 2, 1999; revisions requested Jan 11, 2000; revisions received March 21, 2000; accepted for publication April 20, 2000.

Address for reprints: William J. Dreyer, MD, Pediatric Cardiology, MC 2-2280, Texas Children's Hospital, 6621 Fannin, Houston, TX 77030 (E-mail: wdreyer@bcm.tmc.edu).

Copyright (C) 2000 by The American Association for Thoracic Surgery

0022-5223/2000 $\$ 12.00+0 \quad \mathbf{1 2 / 1 / 1 0 8 1 6 8}$

doi: $10.1067 / \mathrm{mtc} .2000 .108168$
$\Delta$ complex inflammatory reaction takes place in Aresponse to cardiopulmonary bypass (CPB), occurring in part because of exposure of blood to the extracorporeal circuit and occurring in part because of ischemia-reperfusion of selected tissues. Documented components of this inflammatory reaction include the activation of complement, ${ }^{1-3}$ the increased surface expression of adhesion molecules on circulating leukocytes, ${ }^{4-6}$ and the presence of inflammatory cytokines within the systemic circulation. ${ }^{7-9}$ One principal cytokine released into the circulation after $\mathrm{CPB}$ is interleukin 6 (IL-6), a pleiotropic molecule with biologic activity that includes the induction of intercellular adhesion molecule-1 (ICAM-1) expression on cardiac 
myocytes (thus supporting neutrophil-myocyte adhesion $),{ }^{10}$ the inhibition of apoptosis, ${ }^{11,12}$ and direct negative inotropic properties on cardiac myocytes as well. ${ }^{13,14}$ The source of IL-6 release into the systemic circulation after CPB is uncertain; however, the presence of IL-6 messenger RNA (mRNA) in myocytes within the border zone of myocardial infarctions after canine coronary artery occlusion-reperfusion experiments has been documented. ${ }^{15}$ Until recently, it was thought that, during $\mathrm{CPB}$, the myocardium would be protected from inflammatory injury by hypothermia and cardioplegic arrest. Yet recent studies suggest that the myocardium may participate in or may be affected by the inflammatory response to $\mathrm{CPB}$ to a greater extent than previously recognized. Whether IL-6 induction occurs within the myocardium after CPB is unknown. It was the purpose of this study to characterize the expression of IL- 6 and ICAM-1 within the myocardium after CPB by examining myocardial biopsy specimens obtained at different times after the bypass procedure for the presence of IL- 6 and ICAM-1 mRNA. Leukocytes isolated from the peripheral circulation before, during, and after CPB were also examined for IL-6 mRNA expression.

\section{Methods}

Animal preparation. Healthy adult mixed breed dogs $(16-25 \mathrm{~kg})$ were anesthetized with sodium pentobarbital (30 $\mathrm{mg} / \mathrm{kg}$ ), intubated, and mechanically ventilated with $100 \%$ oxygen. After femoral arterial cannulation, ventilatory rate and tidal volume were adjusted to establish a normal $\mathrm{pH}$ and $\mathrm{PCO}_{2}$, as determined by arterial blood gas. After midline thoracotomy, $\mathrm{CPB}$ was achieved by selective venous cannulation of the inferior and superior venae cavae, with arterial return directed into the distal aortic arch. The bypass circuit consisted of a cardiotomy reservoir and variable-prime membrane oxygenator (Cobe Cardiovascular, Inc), a heat exchanger, and a roller pump (Sarns/3M Healthcare). The circuit was primed with 40 to $50 \mathrm{~mL} / \mathrm{kg}$ body weight of lactated Ringer's solution. Before $\mathrm{CPB}$, the circuit was demonstrated to be free of endotoxin by means of Limulus amebocyte lysate assay.

Two groups of animals were included in this study. The first group, designated the CPB group, consisted of 9 animals that underwent CPB with an aortic crossclamp time of 60 minutes and total bypass times of approximately 90 minutes. Before cannulation, each animal was given porcine heparin sodium, $100 \mathrm{U} / \mathrm{kg}$, for anticoagulation. After the aorta was crossclamped, potassium cardioplegic solution (Plegisol, Abbott Laboratories) cooled to $4^{\circ} \mathrm{C}$ was administered in a prograde fashion until complete arrest of the heart was achieved. The animals were cooled to a rectal temperature of $24^{\circ} \mathrm{C}$ to $28^{\circ} \mathrm{C}$. Flow was maintained during bypass at 60 to 70 $\mathrm{mL} \cdot \mathrm{kg}^{-1} \cdot \mathrm{min}^{-1}$ at a pressure of 40 to $60 \mathrm{~mm} \mathrm{Hg}$. After rewarming to $37^{\circ} \mathrm{C}$ and weaning from $\mathrm{CPB}$, animals received protamine sulfate $1 \mathrm{mg} / 100 \mathrm{U}$ heparin delivered for reversal of anticoagulation. Animals were once again ventilated with $100 \%$ oxygen. Tidal volume and ventilator rate were set to optimize $\mathrm{pH}$ and $\mathrm{PCO}_{2}$. Animals were then maintained with an open chest for $3(n=4), 6(n=4)$, or $9(n=1)$ hours. At the end of the reperfusion interval, animals were killed with an overdose of sodium pentobarbital, and their hearts were immediately removed for the collection of tissue samples. Technique was maintained as constant as possible from 1 animal to the next.

The second group consisted of 4 animals designated as sham-bypass controls. These animals served as controls in that they received general anesthesia and mechanical ventilation similar to the animals in group I. In addition, they underwent midline thoracotomy and cannula placement, but they were not placed on CPB. Also, these animals were not subjected to cooling and rewarming or hemodilution. These animals, however, did receive heparin and protamine at a time and in an amount similar to the CPB animals and were maintained with an open chest in a time-matched fashion to those animals undergoing 3 hours of reperfusion in group I.

Approval. The animal studies in this article were reviewed and approved by the Baylor College of Medicine Animal Care and Use Committee. All animals received humane care in compliance with the "Principles of Laboratory Animal Care" formulated by the National Society for Medical Research and the "Guide for the Care and Use of Laboratory Animals" prepared by the Institute of Laboratory Animal Resources and published by the National Institutes of Health (National Institutes of Health publication No. 86-23, revised 1985).

Neutrophil isolation procedure. Forty milliliters of whole blood was collected from the experimental animals into citrate-phosphate-dextrose buffer before CPB, immediately after $\mathrm{CPB}$, and at 3 hours of reperfusion. Granulocyte and mononuclear cell (monocyte-lymphocyte) fractions were isolated on a commercially available single-density gradient (NIM, Cardinal Assoc, Inc) according to manufacturer's instructions.

Northern blot analysis. Myocardial biopsy material was immediately snap frozen in liquid nitrogen on collection and stored at $-80^{\circ} \mathrm{C}$ until RNA extraction. RNA extraction was performed from leukocyte samples immediately after leukocyte isolation. RNA was extracted by the acid guanidinium phenol chloroform solvent extraction method. Northern analysis of isolated RNA was subsequently performed with $1 \%$ agarose formaldehyde denaturing gels and capillary transfer to nitrocellulose membranes (Immobilon NC, Millipore Corporation) by standard procedures. Loading of RNA was monitored by ethidium bromide staining. Membranes were prehybridized for 2 hours in buffer containing $50 \%$ formamide; $\mathrm{NaCl}, 0.8 \mathrm{~mol} / \mathrm{L} ; \mathrm{NaPO}_{4}, 50 \mathrm{mmol} / \mathrm{L}$; ethylenediamine tetraacetic acid, $1 \mathrm{mmol} / \mathrm{L} ; 2.5 \times$ Denhart solution; and herring sperm DNA. They were then hybridized overnight at $58^{\circ} \mathrm{C}$ in the same buffer containing $3 \times 10^{7} \mathrm{cpm}$ phosphorus 32-labeled antisense transcripts of dog IL-6 and dog ICAM-1. After being washed, filters were exposed to Kodak XAR-5 x-ray film, as previously described. 


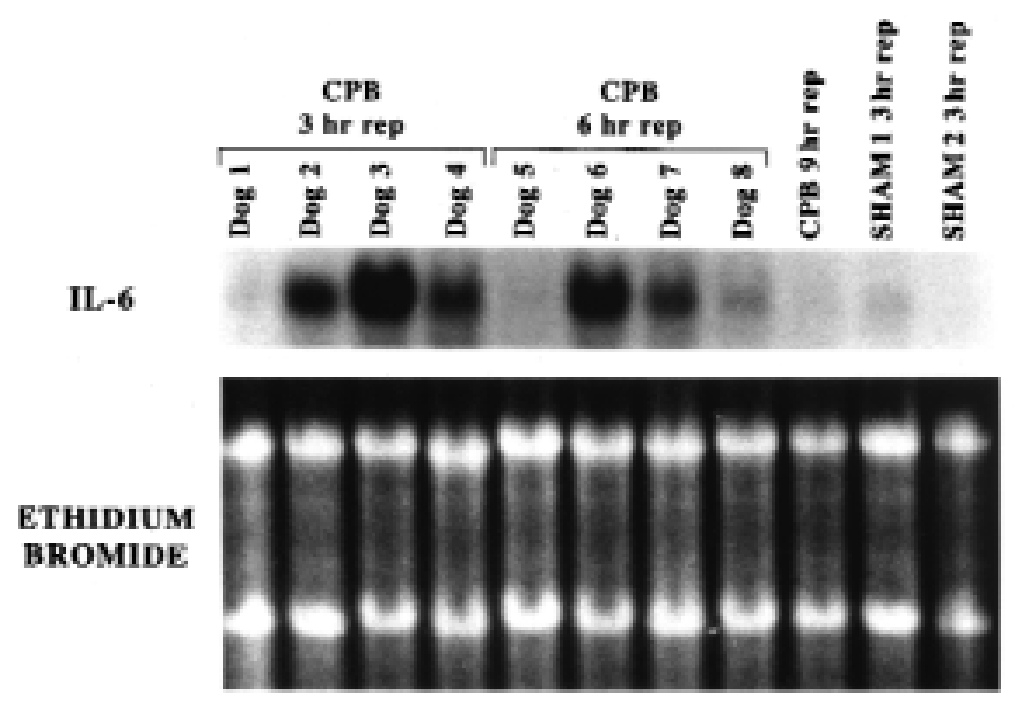

Fig 1. Northern blot analysis of IL-6 mRNA expression in the myocardium of animals undergoing CPB or in timematched sham-bypass control animals $(S H A M)$. Samples from dogs 1 to 4 were obtained 3 hours into recovery after completion of the bypass procedure. Samples from dogs 5 to 8 were obtained 6 hours into recovery after completion of CPB. A single animal from 9 hours of reperfusion and two sham-bypass animals are included.

RNA template preparation for reverse transcriptase-polymerase chain reaction. Myocardial tissue samples were first homogenized in Trizol reagent (Gibco-BRL) by means of disposable RNase-free pestles (PGC Scientific). Total RNA was isolated according to the manufacturer's instructions.

Reverse transcription and polymerase chain reaction. Reverse transcription-polymerase chain reaction (RT-PCR) was used for the detection of transcripts. For the synthesis of complementary DNA (cDNA), $2 \mu \mathrm{L}$ of extracted RNA was mixed with $6 \mu \mathrm{g}(2 \mu \mathrm{L}$ of $3 \mathrm{mg} / \mathrm{mL})$ of random primers (Gibco-BRL) and 7.2 $\mu \mathrm{L}$ of diethyl-pyrocarbonate-treated water in the presence of $0.5 \mathrm{U}(0.5 \mu \mathrm{L})$ of Prime RNase inhibitor (5' -3', Inc). This mixture was heated to $95^{\circ} \mathrm{C}$ for 5 minutes and then snap-cooled on ice. To this we added 4 $\mu \mathrm{L}$ of $5 \times$ reverse transcriptase buffer (Gibco-BRL), $2 \mu \mathrm{L}$ of $100 \mathrm{mmol} / \mathrm{L}$ dithiothreitol, $0.8 \mu \mathrm{L}$ of $25 \mathrm{mmol} / \mathrm{L}$ deoxyribonucleoside triphosphates, another $0.5 \mu \mathrm{L}$ of RNase inhibitor, and $200 \mathrm{U}(1 \mu \mathrm{L})$ of Moloney murine leukemia virus reverse transcriptase (Gibco-BRL). The samples were incubated at $37^{\circ} \mathrm{C}$ for 1 hour, followed by 5 minutes at $95^{\circ} \mathrm{C}$ to inactivate the enzyme. Two microliters of this firststrand cDNA was subjected to PCR amplification to detect $\beta$-actin or IL-6 RNA.

To confirm the isolation of RNA from the tissue samples and confirm that equivalent quantities of RNA were used in each RT-PCR reaction, we subjected $2 \mu \mathrm{L}$ of cDNA to PCR with $\beta$ actin-specific primers. The template was amplified in a $20-\mu \mathrm{L}$ reaction, containing $1 \times$ PCR buffer (Gibco-BRL), $2.5 \mathrm{mmol} / \mathrm{L}$ magnesium chloride, $0.25 \mathrm{mmol} / \mathrm{L}$ deoxyribonucleoside triphosphates, $0.5 \mu \mathrm{mol} / \mathrm{L}$ oligonucleotide primers, and $2.5 \mathrm{U}$ of
Taq DNA polymerase (Gibco-BRL). After an initial 5-minute incubation at $94^{\circ} \mathrm{C}, 35$ rounds of amplification were performed by means of a Stratagene RoboCycler thermal cycler (Stratagene) under the following conditions: $94^{\circ} \mathrm{C}$ for $45 \mathrm{sec}-$ onds, $64^{\circ} \mathrm{C}$ for 45 seconds, and $72^{\circ} \mathrm{C}$ for 45 seconds. This was followed by a $72^{\circ} \mathrm{C}$ incubation for 5 minutes.

PCR was used as described for the amplification of $\beta$-actin transcripts to detect IL-6 RNA. All PCR products were detected by $1.75 \%$ agarose gel electrophoresis.

Primers were as follows: IL-6: Ca-IL6-1, CTGGTGATGGCTACTGCTTTC; Ca-IL6-2RT, TTTAGCATCTGGACCAGGATC (product $=405 \mathrm{bp}$ ) and $\beta$-actin: $\beta$-ACT-1RT, TACATGGCTGGGGTGTTGAA; $\beta$-ACT-4, CATGGATGATGATATCGCCG (product $=399 \mathrm{bp}$ ).

In situ hybridization. Immediately after collection, canine myocardial tissue was immersion fixed in $\mathrm{B} * 5$ overnight and subsequently embedded in paraffin. Threemicrometer sections were cut with a Leica microtome (Leica Microsystems). Sections for in situ hybridization were hybridized overnight at $42^{\circ} \mathrm{C}$ with digoxigenin-labeled sense and antisense IL- 6 probes. Detection was performed by using alkaline phosphatase-conjugated antidigoxigenin antibody.

\section{Results}

Northern blot and RT-PCR analysis. Northern blot analysis was performed on myocardial tissue samples looking for induction of both IL-6 and ICAM- 1 genes. As depicted in Fig 1, 3 of the 4 CPB dogs at 3 hours of reperfusion and 3 of the 4 CPB dogs at 6 hours of reperfusion 


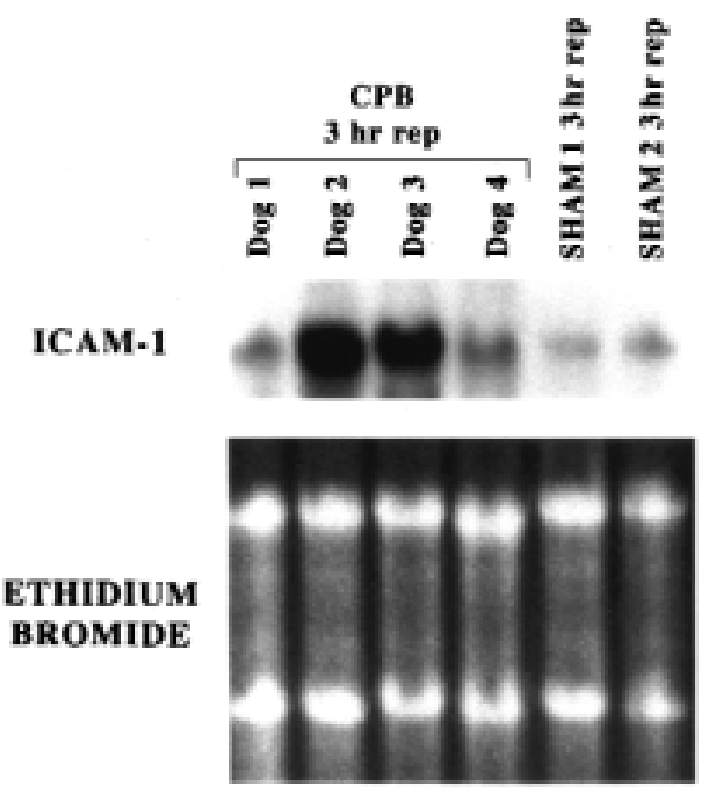

Fig 2. Northern blot analysis of ICAM-1 mRNA expression in the myocardium of the same animals undergoing CPB with 3 hours recovery, as depicted in Fig 1 (lanes 1-4). Lanes 5 and 6 represent 2 time-matched sham-bypass control animals (SHAM).

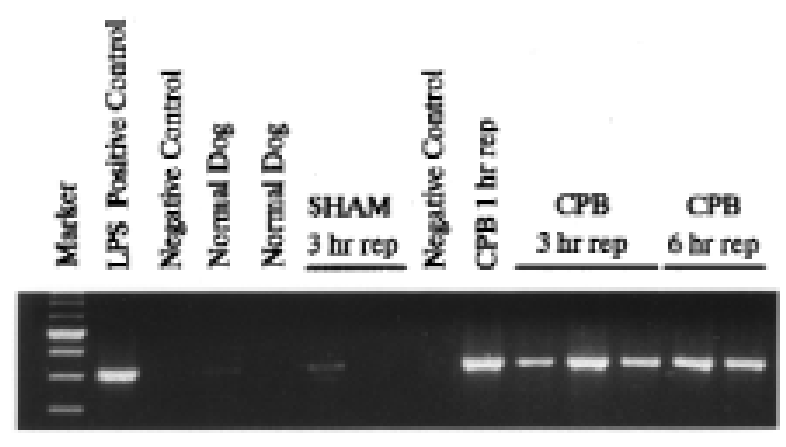

Fig 3. RT-PCR experiment demonstrating canine myocardial IL-6 mRNA expression 1, 3, and 6 hours after the completion of $\mathrm{CPB}$ and in a lipopolysaccharide (LPS)-treated positive control animal. Myocardium from 2 normal uninstrumented dogs and 2 sham-bypass control $\operatorname{dogs}$ (SHAM) failed to express IL-6 mRNA despite message amplification with the PCR technique.

demonstrated a substantial increase in IL-6 mRNA expression when compared with sham-bypass control animals. As demonstrated in Fig 2, ICAM-1 mRNA also was expressed in the CPB dogs at 3 hours of reperfusion. The pattern of ICAM-1 expression roughly paralleled that of IL-6 in that ICAM- 1 was most strongly expressed in dogs 2 and 3, where IL-6 was most strongly expressed

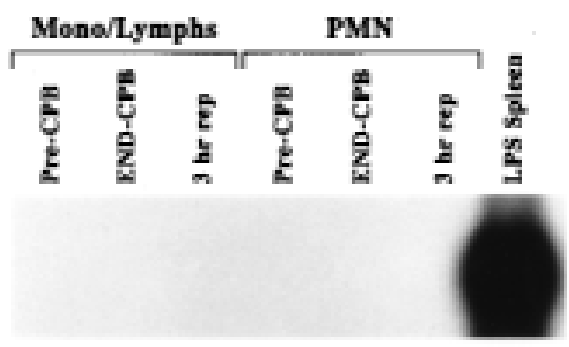

IL-6

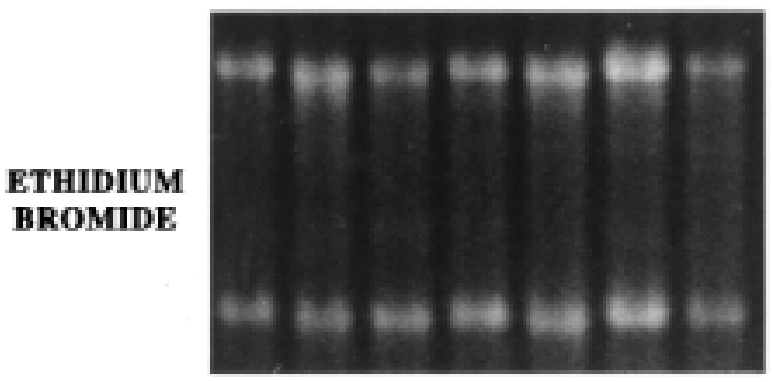

Fig 4. Representative Northern blot analysis of IL-6 mRNA expression in circulating monocytes-lymphocytes and neutrophils $(P M N)$ before CPB (Pre-CPB), at the completion of CPB (End-CPB), and at 3 hours into recovery after CPB $(3 \mathrm{hr}$ rep), as well as in spleen from a lipopolysaccharide (LPS)stimulated positive control animal.

as well. In dogs 1 and 4 ICAM-1 expression was less, although clearly increased when compared with shambypass control animals. IL-6 was either absent ( $\operatorname{dog} 1)$ or less strongly expressed (dog 4) in these dogs as well. At 6 hours of reperfusion, ICAM-1 was minimally expressed in the CPB dogs and did not parallel IL-6 expression (data not shown).

As depicted in Fig 3, RT-PCR analysis demonstrated that even with gene product amplification, IL-6 mRNA was minimally present or not expressed in normal dogs or in dogs undergoing the sham-bypass procedure. IL6 induction was limited to those dogs undergoing CPB with cardioplegic arrest of the heart.

In contrast to the myocardial tissue samples of dogs undergoing CPB, Northern blot analysis of circulating leukocytes, both neutrophils and mononuclear cells, failed to demonstrate any evidence of IL- 6 mRNA expression at any of the time points tested: before, immediately after, or 3 hours after $\mathrm{CPB}$. This was true in 4 of 4 dogs tested (Fig 4).

In situ hybridization. In situ hybridization for IL-6 at 3 hours of reperfusion demonstrated a diffuse transmural staining of cardiac myocytes (Fig 5, A). Note that this staining pattern occurred largely in the absence of marginated inflammatory cells. This pattern 

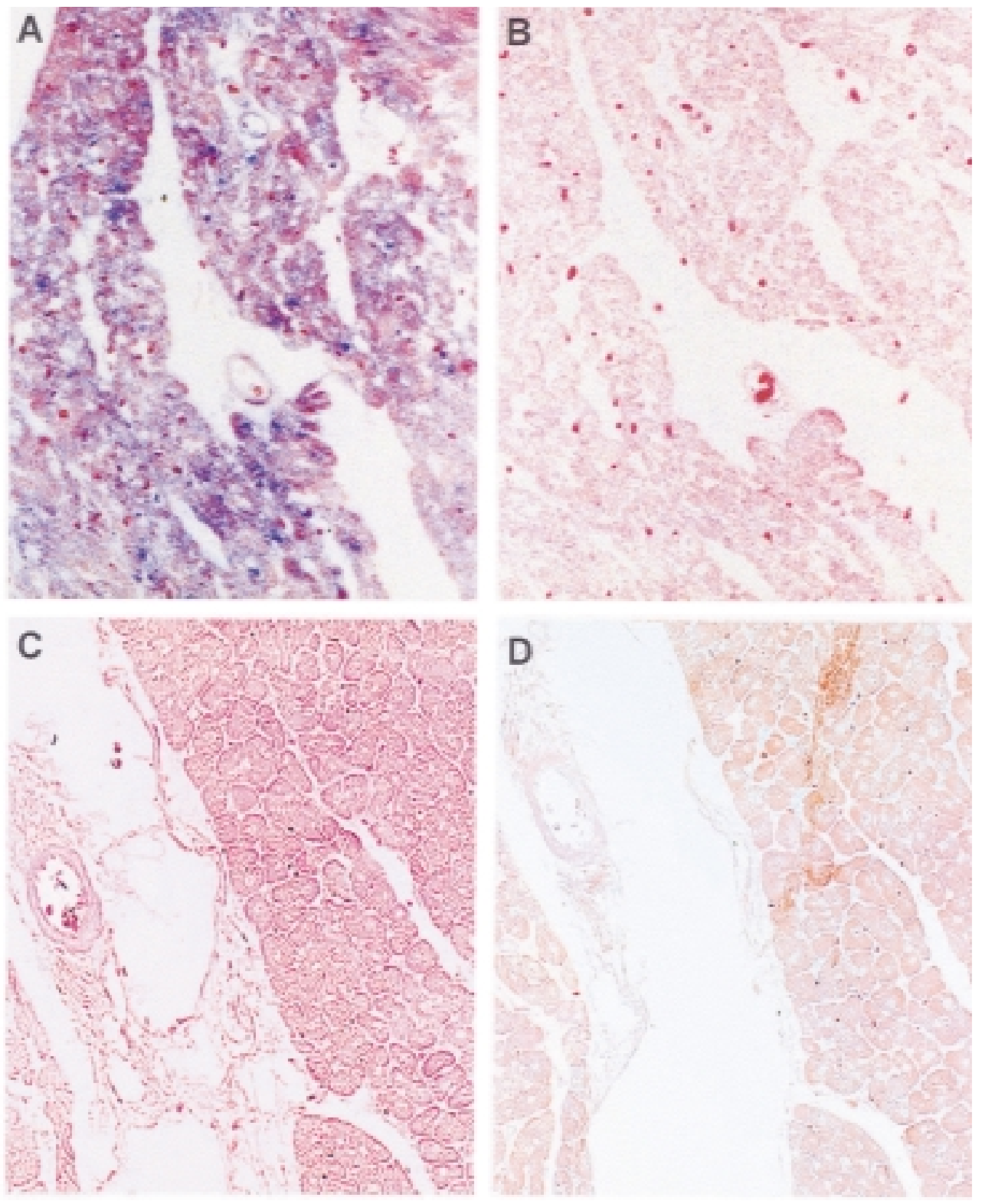

Fig 5. Representative IL-6 in situ hybridization results in histologic sections of canine myocardium. A, In situ hybridization with the antisense canine IL-6 probe in myocardium from a dog reperfused for 3 hours after the completion of CPB. The blue reaction product is indicative of the presence of IL-6 mRNA within cardiac myocytes. B, In situ hybridization with the sense canine IL-6 negative control in a serial section from the same animal represented in A. C, In situ hybridization with the antisense canine IL-6 probe in myocardium from a sham-bypass control dog time matched to 3 hours of reperfusion after CPB. There is no indication of IL- 6 mRNA staining in this section. D, In situ hybridization with the sense canine IL-6 negative control in a serial section from the same animal represented in $\mathbf{C}$. Note, all sections were counterstained with eosin.

of staining from animal to animal was consistent with the results of Northern blot analysis for IL-6 induction, as described above. In contrast, in situ hybridization studies in sham-bypass control animals failed to demonstrate IL-6 induction within the cardiac myocytes (Fig 5, C).

\section{Discussion}

A number of investigators have now documented that IL-6 is released into the peripheral circulation of patients undergoing CPB with moderate degrees of hypothermia. Although the exact time profile of IL-6 release has varied somewhat from study to study, all 
have demonstrated an increase in plasma IL- 6 within a few hours after the completion of CPB that has persisted out to 24 hours. ${ }^{7-9}$ The source of this IL-6 production, however, has not been conclusively identified. It has been commonly assumed that circulating inflammatory cells activated by exposure to the extracorporeal circuit release IL-6 into the peripheral circulation. However, two recent studies have suggested that the heart may be a source of IL- 6 production after bypass by demonstrating increased coronary sinus blood levels of IL- 6 relative to that seen in the peripheral circulation. ${ }^{16,17}$ Neither of these studies identified a tissue source within the heart that was capable of producing IL-6, and candidate tissues could include cardiac myocytes, vascular endothelial cells, or infiltrating inflammatory cells. Other recent studies have demonstrated that cardiac myocytes can produce IL-6. Sawa, ${ }^{17}$ Yamauchi-Takihara, ${ }^{18}$ and their colleagues demonstrated in vitro that IL-6 is increased in the supernatant of cultured myocytes from Wistar rats when exposed to hypoxia and reoxygenation. In a similar fashion Gwechenberger and associates ${ }^{15}$ recently demonstrated that isolated canine myocytes express IL6 mRNA in response to a variety of stimuli, including tumor necrosis factor $\alpha$ (TNF)- $\alpha$, IL-1 $\beta$, endotoxin, and cardiac lymph collected after ischemia-reperfusion. Furthermore, their study documented reperfusiondependent expression of IL-6 mRNA in the viable border zone of a myocardial infarction within 1 hour of reperfusion. Our study has clearly demonstrated for the first time the induction of IL-6 in vivo in canine cardiac myocytes within the first 3 hours of recovery after CPB and before the presence of a significant inflammatory infiltrate. We also demonstrated that IL-6 mRNA induction is not evident in circulating leukocytes before, during, or within the first 3 hours after the CPB procedure as commonly believed.

The stimulus for myocyte IL-6 production in this context is unknown, but direct ischemic-hypoxic injury to the cell with subsequent reperfusion is a possibility. The extent of myocardial ischemia induced during CPB was not vigorously explored in this study. Myocardial temperature and $\mathrm{pH}$ were not measured directly, nor was myocardial blood flow measured during aortic crossclamping. Nonoxygenated crystalloid cardioplegic solutuion was used in this study rather than blood cardioplegic solution, and the extent to which this may have affected myocardial oxygenation is uncertain. There appeared to be variability between CPB animals in the expression of both IL-6 and ICAM-1 mRNA, and the extent to which variation in the ischemic insult to the myocardium of these animals may have contributed to this observed difference remains speculative.
Alternatively, IL-6 induction could have occurred because of the local release of an upstream inflammatory cytokine. In coronary artery occlusion-reperfusion experiments, resident cardiac mast cells have been demonstrated to release TNF- $\alpha,{ }^{19}$ and as discussed above, TNF- $\alpha$ has been demonstrated to stimulate the induction of IL-6 in isolated cardiac myocytes in vitro. Also, recent evidence from rats suggests that the induction of nuclear factor $\mathrm{KB}$ occurs in the myocardium subjected to occlusion-reperfusion. IL-6 is known to have a $\kappa \mathrm{B}$ response element, and an increase in IL-6 could, in part, be due to the upstream induction of nuclear factor $\mathrm{\kappa B} .{ }^{20}$

The fact that IL-6 is produced by cardiac myocytes in the context of CPB raises interesting questions as to its physiologic significance, pathophysiologic significance, or both. Despite the documentation of high levels of IL-6 in the plasma after CPB, its role remains largely unknown. Several important possibilities, however, do exist. In this study we documented that ICAM1 mRNA was increased within the first 3 hours after CPB along with IL-6 expression, suggesting a possible relationship between the two. This observation is important because studies by Youker, ${ }^{10}$ Smith, ${ }^{21}$ Entman, ${ }^{22}$ and their coworkers have demonstrated that neutrophil-induced oxidative injury to cardiac myocytes is dependent on neutrophil-myocyte adherence mediated by neutrophil CD18 expression and myocyte ICAM-1 expression. In vitro cardiac myocyte ICAM-1 expression can be affected by a variety of cytokines, including IL-1, TNF- $\alpha$, and IL-6. IL-6, however, appears to be the physiologically relevant cytokine as the ability of postischemic cardiac lymph to induce myocyte ICAM-1 expression was completely inhibited by a neutralizing antibody to human IL-6. Also, leukocyte-mediated injury to the myocardium after CPB appears to be a relevant mechanism of myocardial dysfunction after CPB as post-CPB leukocyte depletion appears to enhance left ventricular systolic function. ${ }^{23}$

IL-6 may also contribute to myocardial stunning postoperatively. Finkel and associates ${ }^{13}$ have demonstrated that the addition of recombinant human IL- 6 to the medium bathing isolated hamster papillary muscles resulted in a concentration-dependent, reversible, negative inotropic effect that was blocked by the administration of the nitric oxide synthase inhibitor $\mathrm{N}$-monomethy-L-arginine. Also, a role for cytokine-inducible nitric oxide synthase in cardiac myocytes has been implicated as a mechanism of myocardial contractile dysfunction associated with the systemic inflammatory response syndrome ${ }^{14}$ and associated with myocardial infarction. ${ }^{24}$ Finally, one study, performed in 3-week-old piglets, suggests that the L-argi- 
nine-nitric oxide pathway is also of pathophysiologic significance to the development of myocardial dysfunction after $\mathrm{CPB}{ }^{25}$

Yet one must consider what selective advantage myocardial IL-6 production might have to the myocardium. As an alternative action to the potential mechanisms of myocyte injury detailed above, IL-6 could prove to have a cardioprotective role after CPB by inhibiting cardiac myocyte apoptosis. Apoptosis has recently been recognized as a mechanism of myocyte death in the failing myocardium associated with chronic congestive heart failure. ${ }^{26}$ In addition, apoptosis has been identified as a mechanism of myocyte loss in acute ischemia and reperfusion injury in the rabbit heart ${ }^{27}$ and in cultured neonatal rat cardiomyocytes exposed to hypoxia. ${ }^{28}$ Little is known about the induction of apoptosis in the myocardium protected by hypothermic cardioplegic arrest during $\mathrm{CPB}$; however, a recent study by Aebert and colleagues ${ }^{29}$ demonstrated histopathologic evidence of DNA fragmentation by nick end labeling consistent with apoptosis in atrial biopsy specimens from patients undergoing $\mathrm{CPB}$ with cardioplegic arrest and moderate hypothermia. His study also demonstrated, by Northern blot analysis, induction of the protooncogenes $c$-fos and $c$-jun, which may act as transcription factors for other genes involved in the apoptotic pathway. Whether IL-6 has a regulatory role in the apoptotic pathway of cardiac myocytes is presently unknown, although IL-6 appears to be protective against apoptosis in other cell types. ${ }^{11,12}$ In addition, a novel cardiac cytokine, cardiotrophin 1, has recently been described and appears to promote cardiac myocyte survival by activation of an antiapoptotic signaling pathway. Cardiotrophin 1 is a member of the IL- 6 family of cytokines, all of which exert their biologic effects through the shared signaling subunit gp $130 .{ }^{30}$ Whether cardiotrophin 1 and IL6 share an antiapoptotic effect in the myocardium is at present unknown.

In summary, what is known from this study is that CPB with cold cardioplegic arrest appears to be a sufficient stimulus to induce IL-6 synthesis in cardiac myocytes. Although the exact mechanism of induction and the role that IL-6 performs in the postoperative setting requires further investigation, it appears that the local production of IL- 6 could play a pivotal role in the regulation of myocardial function postoperatively.

\section{REFERENCES}

1. Chenoweth DE, Cooper SW, Hugli TE, Stewart RW, Blackstone $\mathrm{EH}$, Kirklin JW. Complement activation during cardiopulmonary bypass: evidence for generation of $\mathrm{C} 3 \mathrm{a}$ and $\mathrm{C} 5 \mathrm{a}$ anaphylatoxins. N Engl J Med 1981;304:497-503.

2. Kirklin JK, Westaby S, Blackstone EH, Kirklin JW, Chenoweth DE, Pacifico AD. Complement and the damaging effects of cardiopulmonary bypass. J Thorac Cardiovasc Surg 1983;86:845-57.

3. Tamiya T, Yamasaki M, Maeo Y, Yamashiro T, Ogoshi S, Fujimoto S. Complement activation in cardiopulmonary bypass, with special reference to anaphylatoxin production in membrane and bubble oxygenators. Ann Thorac Surg 1988;46:47-57.

4. Kappelmayer J, Bernabei A, Gikakis N, Edmunds LH Jr, Colman RW. Upregulation of Mac-1 surface expression on neutrophils during simulated extracorporeal circulation. J Lab Clin Med 1993;121:118-26.

5. Dreyer WJ, Michael LH, Millman EE, Berens KL. Neutrophil activation and adhesion molecule expression in a canine model of open heart surgery with cardiopulmonary bypass. Cardiovasc Res 1995;29:775-81.

6. Gillinov AM, Bator JM, Zehr KJ, et al. Neutrophil adhesion molecule expression during cardiopulmonary bypass with bubble and membrane oxygenators. Ann Thorac Surg 1993;56:847-53.

7. Steinberg JB, Kapelanski DP, Olson JD, Weiler JM. Cytokine and complement levels in patients undergoing cardiopulmonary bypass. J Thorac Cardiovasc Surg 1993;106:1008-16.

8. Kawamura T, Wakusawa R, Okada K, Inada S. Elevation of cytokines during open-heart surgery with cardiopulmonary bypass: participation of interleukin 8 and 6 in reperfusion injury. Can J Anaesth 1993;40:1016-21.

9. Hennein HA, Ebba H, Rodriguez JL, et al. Relationship of the proinflammatory cytokines to myocardial ischemia and dysfunction after uncomplicated coronary revascularization. J Thorac Cardiovasc Surg 1994;108:626-35.

10. Youker K, Smith CW, Anderson DC, et al. Neutrophil adherence to isolated adult cardiac myocytes: induction by cardiac lymph collected during ischemia and reperfusion. J Clin Invest 1992;89:602-9.

11. Umegaki H, Yamada K, Naito M, Kamayama T, Iguchi A, Nabeshima T. Protective effect of interleukin- 6 against the death of PC12 cells caused by serum deprivation or by the addition of a calcium ionophore. Biochem Pharmacol 1996;52:911-6.

12. Schwartz MMK, Hawley RG. Prevention of myeloma cell apoptosis by ectopic $b c l-2$ expression or interleukin 6-mediated upregulation of $b c l-x L$. Can Res 1995;55:2262-5.

13. Finkel MS, Oddis CV, Jacob TD, Watkins SC, Hattler BG, Simmons RL. Negative inotropic effects of cytokines on the heart mediated by nitric oxide. Science 1992;257:387-9.

14. Ungureanu-Longrois D, Balligand JL, Kelly RA, Smith TW. Myocardial contractile dysfunction in the systemic inflammatory response syndrome: role of a cytokine-inducible nitric oxide synthase in cardiac myocytes. J Mol Cell Cardiol 1995;27:155-67.

15. Gwechenberger M, Mendoza LH, Youker KA, et al. Cardiac myocytes produce IL- 6 in culture and in the viable border zone of reperfused infarctions. Circulation 1999;99:546-51.

16. Wan S, DeSmet JM, Barvais L, Goldstein M, Vincent JL, LeClerc $\mathrm{JL}$. Myocardium is a major source of proinflammatory cytokines in patients undergoing cardiopulmonary bypass. J Thorac Cardiovasc Surg 1996;112:806-11. 
17. Sawa $Y$, Ichikawa $H$, Kagiasaki K, Ohata $T$, Matsuda $H$. Interleukin-6 derived from hypoxic myocytes promotes neutrophil-mediated reperfusion injury in myocardium. J Thorac Cardiovasc Surg 1998;116:511-7.

18. Yamauchi-Takihara K, Ihara U, Ogato A, Yoshizaki K, Azuma J, Kishimoto T. Hypoxic stress induces cardiac myocyte-derived interleukin-6. Circulation 1995;91:1520-4.

19. Frangogiannis NG, Lindsey ML, Michael LH, et al. Resident cardiac mast cells degranulate and release preformed TNF- $\alpha$, initiating the cytokine cascade in experimental canine myocardial ischemia/reperfusion. Circulation 1998;98:699-710.

20. Chandrasekar B, Streitman JE, Colston JT, Freeman GL. Inhibition of nuclear factor $\mathrm{\kappa B}$ attenuates proinflammatory cytokine and inducible nitric-oxide synthase expression in postischemic myocardium. Biochim Biophys Acta 1998;1406:91-106.

21. Smith CW, Entman ML, Lane CL, et al. Adherence of neutrophils to canine cardiac myocytes in vitro is dependent on intercellular adhesion molecule-1. J Clin Invest 1991;88:1216-23.

22. Entman ML, Youker K, Shoji T, et al. Neutrophil induced oxidative injury of cardiac myocytes: a compartmented system requiring CD11b/CD18-ICAM-1 adherence. $\mathrm{J}$ Clin Invest 1992;90:1335-45.

23. Wilson IC, DiNatale JM, Gillinov AM, Curtis WE, Cameron DE,
Gardner TJ. Leukocyte depletion in a neonatal model of cardiac surgery. Ann Thorac Surg 1993;55:12-9.

24. Wildhirt SM, Dudek RR, Suzuki H, Bing RJ. Involvement of inducible nitric oxide synthase in the inflammatory process of myocardial infarction. Int J Cardiol 1995;50:253-61.

25. Morita K, Sherman MP, Buckberg GD, et al. Studies of hypoxemic/reoxygenation injury: without aortic clamping $\mathrm{v}$ role of the L-arginine nitric oxide pathway-the nitric oxide paradox. J Thorac Cardiovasc Surg 1995;110:1200-11.

26. Arula J, Haider N, Virmani R, et al. Apoptosis in myocytes in end-stage heart failure. N Engl J Med 1996;335:1182-9.

27. Gottlieb RA, Burleson KO, Kloner RA, Babior BM, Engler RL. Reperfusion injury induces apoptosis in rabbit cardiomyocytes. J Clin Invest 1994;94:1621-8.

28. Tanaka M, Ito H, Adachi S, et al. Hypoxia induces apoptosis with enhanced expression of fas antigen messenger RNA in cultured neonatal rat cardiomyocytes. Circ Res 1994;75:426-33.

29. Aebert H, Cornelius T, Birnbaum DE, Seigel AV, Riegger GAJ, Schunkert H. Induction of early immediate genes and programmed cell death following cardioplegic arrest in human hearts. Eur J Cardiothorac Surg 1997;12:261-7.

30. Sheng Z, Knowlton K, Chen J, Hoshijima M, Brown JH, Chief KR. Cardiotrophin 1 (CT-1) inhibition of cardiac myocyte apoptosis via a mitogen-activated protein kinase-dependent pathway. J Biol Chem 1997;272:5783-91. 